\title{
Phase instability of the topmost surface layer of Inconel-718 superalloy in low-temperature gas carburization atmosphere, revealed by means of $(\mathrm{HR})(\mathrm{S}) \mathrm{T} E \mathrm{M}$
}

\author{
C. Sârbu ${ }^{1, *}$ \\ 1 National Institute of R\&D for Materials Physics (NIMP) 405A Atomistilor street, Măgurele, Romania \\ * Correspondence: crnl_srbu@yahoo.com; Scopus ID: 7006618808
}

The surface microstructure modifications induced by the industrial treatments with the effect of enhancement of the surface engineering parameters in metallic alloys (hardness, wear, corrosion resistance) are utterly important. The recently invented, industrially successful surface hardening by carburization of 316L stainless steel (SS) in gas atmosphere at low-temperature (LT) [1] was extended with similar results to the Ni-Fe base Inconel-718 superalloy (IN-718) [3] and to several other alloys. The accepted model of surface microstructure modification due to processing is not based on full data about the modified topmost layer microstructure. It is missing the visualization of the new microstructure by means of (HR)(S)TEM and analysis. The effect of LT gas carburization is currently explained by a model of surface grains lattice dilatation due to the so called colossal carbon supersaturation (LTCSS) [2] that is not conform to the classical phase diagrams and is claimed to be valid in all alloys including IN-718 [4]. Our work reports new findings that reveal the up to now unknown nanostructure of the topmost carburized $\left(\right.$ at $\left.570^{\circ} \mathrm{C}\right)$ layer $\sim 5 \mu \mathrm{m}$ thick of IN-718 and cast doubts on the general validity of the LTCSS. The (HR)(S)TEM and nanoscale analysis were used to reveal the nanostructure of samples prepared in a special way by ion beam milling. We got no evidence of a classical crystalline microstructure of the carburized IN-718 upper-most layer that can match the requests of the LTCSS model. Instead, we put into evidence the nano-structure of the topmost $\sim 5 \mu \mathrm{m}$ thick layer of the carburized surface showing that it consists both (i) in nanocrystalline austenite and carbides and (ii) in an amorphous phase that contains the main alloy elements, with or without carbon (Fig1). Segregated Ni nanoclusters (Fig-2) are occurring at large areas, apparently not including other main alloy elements. A fragmentation mechanism of the topmost surface layer (consisting initially of $\mu \mathrm{m}$-sized grains) can be figured out by starting from the observed segregation in the initial alloy grains of the main alloy elements, agglomerated both inside grains close to grain boundaries (GBs) and at the GBs (Fig-3) and by the segregation of carbon both inside grains along GBs (Fig-4) and outside grains at GBs. Those chemical segregates can be considered as precursors in the process of fragmentation and are proving the phase instability of the surface alloy grains in the LT carburizing gas atmosphere, thereby revealing the chemical reactivity of the IN-718 surface grains with the LT carburization gas mixture. The surface reactivity can be valorized industrially through developing new research for finding novel compositions of LT gaseous mixtures able to modify the engineering properties of the alloys surfaces.

PROCEEDINGS INTERNATIONAL | https://conferenceproceedings.international | 11

Cite This Work: Sârbu, C. Phase instability of the topmost surface layer of Inconel-718 superalloy in low-temperature gas carburization atmosphere, revealed by means of (HR)(S)TEM. Proceedings Int 2019, 1, 001 1-0012. https://doi.org/10.33263/Proceedings1 1.00110012 


\section{Sarbu}

Keywords: superalloy, Inconel-718, colossal carbon supersaturation, HRTEM.

\section{Funding}

Not applicable.

\section{Acknowledgments}

The present research was initiated in the frame of the Core Program funding (project PN-09-450101) granted to NIMP-Magurele by the Romanian ANCSI Agency.

\section{Conflicts of Interest}

The authors declare no conflict of interest.
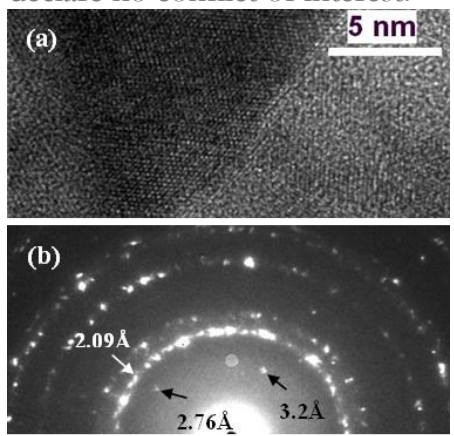

Figure 1. (a) HRTEM of nanocrystalline and amorphous phases observed at $1-1.5 \mu \mathrm{m}$ depth. The $\mathrm{d}(111) \approx 2.09 \AA$ of IN-718 austenite is identified (the largest interplanar distance in austenite). (b) SAED taken from a larger area, where the $3.2 \AA$ and $2.76 \AA$ of $\mathrm{d}(\mathrm{hkl})$ distances are fitting $\mathrm{Cr}$ carbides.

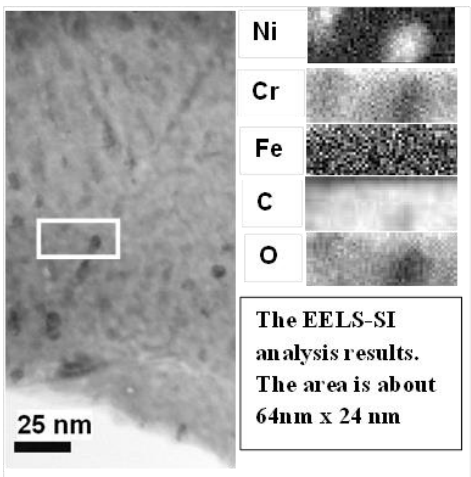

Figure 3. Segregation of Ni nanoclusters at a GB of the initial alloy, observed in STEM-ABF contrast at $3.5-5 \mu \mathrm{m}$ depth. The EELS-SI images clearly show the Ni tendency to

\section{References} separate from $\mathrm{Cr}, \mathrm{Fe}, \mathrm{C}$ and $\mathrm{O}$ in the clusters.

1. Collins, S.R.; Williams, P.C.; Marx, S.V. Low-Temperature Carburization of Austenitic Stainless Steels In: ASM Handbook, Dossett, J., Totten, G.E. (Eds.), Volume 4D, ASM International 2014;

2. Cao, Y.; Ernst, F.; Michal, G.M. Nanoclustered Pd decorated nanocrystalline $\mathrm{Zn}$ doped $\mathrm{SnO}_{2}$ for $\mathrm{ppb} \mathrm{NO}_{2}$ detection at low temperature Acta Mater. 2003, 51, https://doi.org/10.1016/j.snb.2019.05.033.

3. Sharghi-Moshtaghin, R.; Kahn, H.; Ge, Y.; Gu, X.; Martin, F.J.; Natishan, P.M.; Rayne, R,J,l Gary, M.M.; Ernst, F.; Heuer,

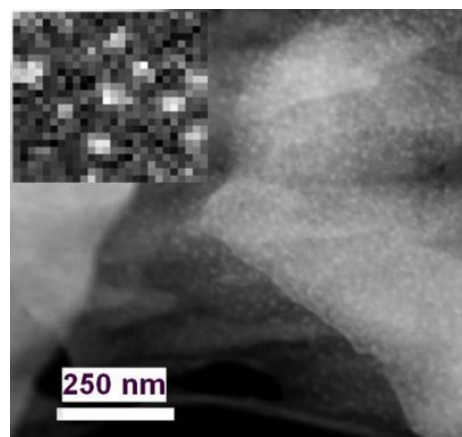

Figure 2. Z-contrast showing Ni clustering, observed on large areas, $3.5-5 \mu \mathrm{m}$ below the free carburized surface. The insert shows an area of $85 \mathrm{~nm} \times 85 \mathrm{~nm}$ where distribution of $\mathrm{Ni}$ nanoclusters is evidenced by EELS-SI as pure white areas. Similar clustering of other alloy main chemical elements was

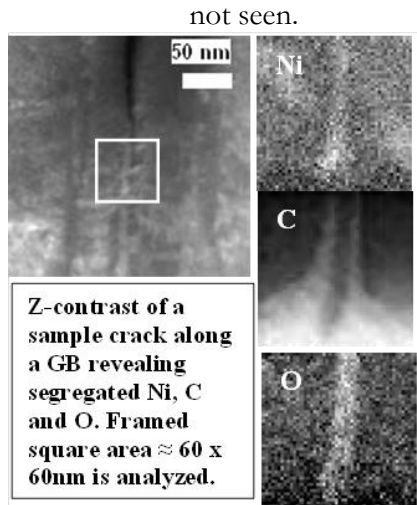

Figure 4. Z-contrast of the initial GB at $4.1-5.3 \mu \mathrm{m}$ depth. EELS-SI reveals the segregation of $\mathrm{Ni}$ along $\mathrm{GB}$ and the agglomeration of $\mathrm{C}$ sideways $\mathrm{GB}$ inside grains. $\mathrm{Ni}$ is probably oxidized.

A.H. Low-Temperature Carburization of the Ni-base Superalloy IN718: Improvements in Surface Hardness and Crevice Corrosion Resistance Metall. Mater. Trans. A 2010, 41 A, 2022, https://doi.org/10.1007/s11661-010-0299-y

4. Li, Z.; Paramasivam, W.N.; Wang, Y.; Anderlogu, O.; Heuer, A.H.; Mayloy, S.A.; Lillard, R.S.; Ernst, F. Surface engineering of IN-718 by low-temperature carburisation: properties and thermal stability. Surface Engineering 2018, 35, 281-293,

https://doi.org/10.1080/02670844.2018.1501936

(C) 2019 by the authors. This article is an open access article distributed under the terms and conditions of the Creative Commons Attribution (CC BY) license (http://creativecommons.org/licenses/by/4.0/). 